\title{
INSTITUCIONES Y CREENCIAS EN LA OBRA DE MICHEL DE CERTEAU
}

\section{INSTITUTIONS AND BELIEFS IN THE WORK OF MICHEL DE CERTEAU}

\author{
Juan D. González-Sanz ${ }^{1}$ \\ ORCID: orcid.org/0000-0002-4344-8353 \\ Universidad de Huelva (España)
}

Recibido: 24-4-2015

Aceptado: 8-9-2015

Resumen: Este artículo pretende profundizar en la dimensión social de la antropología del creer del pensador jesuita francés Michel de Certeau (19251986). Para ello se abordan cuestiones como la concepción certeauniana de política (con un marcado tinte polemológico) y de institución (sin rehuir ni su necesidad ni su tendencia a la corrupción). Posteriormente se explora el modo en que ambos conceptos se relacionan con las creencias.

Palabras-clave: Michel de Certeau, instituciones, creencias, adhesión, corrupción.

\begin{abstract}
This article aims to understand the social dimension of the French Jesuit thinker Michel de Certeau's (1925 to 1986) anthropology of believe. To get it the paper approaches questions as the certeaunian conceptions of politics (with a marked polemological bias) and institution (including its necessity and its tendency to corruption). Finally it is explored how both concepts are related with beliefs.
\end{abstract}

Key-words: Michel de Certeau, institutions, beliefs, joining, corruption.

[1] (juan.gonzalez@denf.uhu.es) Doctor por la Universidad de Huelva (2014), con una tesis titulada Creer, saber y poder. Jalones para una antropología del creer (y del cuidar) en la obra de Michel de Certeau, es profesor sustituto en la Facultad de Enfermería de la Universidad de Huelva. Entre sus publicaciones se encuentran el libro Explorar el día a día (Nexofía, 2010) y artículos como "Elementos para una crítica del saber en Michel de Certeau: apertura, discontinuidad e interés" (Diálogo Filosófico, 90, 2014). Es Secretario de Redacción de La Torre del Virrey. Revista de Estudios Culturales. 


\section{La política: encuentro y conflicto}

Para comprender qué relevancia tiene la dimensión política en el conjunto del pensamiento de Michel de Certeau sobre el creer ${ }^{2}$, es fundamental recordar la situación privilegiada que tiene «el actuar y su inserción social en lo que Michel de Certeau designa en un primer momento como "una historia de la espiritualidad" y, más tarde, como "una antropología del creer" $\|^{3}$. El hecho de que el ser humano esté inmerso en una permanente relación con otros hace que el estudio de la dinámica interna de esta relación sea una de las raíces fundamentales de la dimensión política de la antropología certeauniana del creer. Como ha afirmado Jacques Revel la concepción de lo social en Certeau es la de «una política pensada como la invención de una relación con los otros y con el mundo, que no cesaría de ser redefinida a través de un juego de interrogaciones confrontadas» ${ }^{4}$.

Aunque podría utilizarse el término social para hacer referencia a los aspectos que ocupan este artículo, la preferencia por la palabra política no es casual en el marco del estudio certeauniano de las creencias, ya que para nuestro autor la política (sobre todo en su vertiente institucional) hereda la condición de depósito de creencias que antes tuvo la religión ${ }^{5}$. Para clarificar los términos en que va a desarrollarse este trabajo es necesario abordar una pregunta de base: ¿qué significado tuvo la palabra política para Certeau?

Hay que partir de que para él lo político implica mucho más que aquello a lo que este término puede hoy hacer referencia de una forma general: es un área de la vida que va más allá de lo concerniente a los partidos, al Estado o a sus instituciones. Lo político, lo público, es en el mundo certeauniano una dimensión de encuentro en la que no sobra nadie y que impregna el conjunto de la existencia humana: «Todo es política» ${ }^{6}$.

Como señala Luce Giard(cuya aportación es esencial para dar la relevancia justa a esta cuestión en el conjunto del corpus certeauniano), «de los difíciles años 1940-1944, él [Certeau] había guardado esta convicción:

[2] González-Sanz, J.D.: «Puntales para el estudio de la antropología del creer en Michel de Certeau» en La Torre del Virrey, 12, 2012, pp. 59-69; González-Sanz, J.D.: "Cómo nace una institución. reflexiones sobre -Una política de la lengua- de Michel de Certeau» en Anales del Seminario de Historia de la Filosofía, 2/32, 2015, 567-588.

[3] Giard, L.: «Mystique et politique» cit., p. 37 (la traducción de todos los textoscitados del original francéses del autor).

[4] Revel, J.: op. cit., p. 126.

[5] Certeau, M. de: L'invention cit., p. 260.

[6] Certeau, M. de: La culture cit., p. 70. Ortega señala algo similar al inicio de La rebelión de las masas: «Ni este volumen ni yo somos políticos. El asunto de que aquí se habla es previo a la política y pertenece a su subsuelo», Ortega y Gasset, J.: La rebelión cit., p. 28.

Thémata. Revista de Filosofía №53 (2016) pp.: 195-218. 
nadie puede abstenerse de la esfera pública, ya que nadie puede eludir su parte de responsabilidad política en lo que es combate de todos» ${ }^{7}$. Tanto es así que, como para tantos otros que han vivido bajo el yugo de la tiranía y la violencia, la palabra política tiene en los oídos de Certeau unas connotaciones que, sin ser ingenuas, enmarcan una vivencia profunda de la realidad social del ser humano. Vivencia tremendamente alejada de la comprensión raquítica y disminuida que de lo político reina actualmente en la sociedad europea.

No hay que entender, no obstante, que esta fortaleza de la dimensión pública habría de traducirse en algún tipo de protagonismo personal (del tipo que fuera) por parte de nuestro autor. Más bien Certeau se sitúa, en todo momento, ocupando un escaño en las entrañas oscuras de la democracia. «Este terreno político no es el mío (salvo como ciudadano)»", llegará a afirmar. Desde este lugar discreto irá desarrollando un perseverante y agudo trabajo de crítica, fundamentado y leal.

$\mathrm{Al}$ hilo de la pregunta que nos hacíamos anteriormente pueden destacarse dos vertientes principales de la concepción política certeauniana. En primer lugar, una reivindicación de la alteridad como fuente de riqueza; y en segundo lugar, la toma de conciencia del carácter polémico del encuentro humano.

\subsection{La esencial alteridad}

La alteridad es un concepto central en el pensamiento de Michel de Certeau, que le entronca con una larga tradición intelectual de raigambre dialógica ${ }^{9}$, y que se manifiesta de muy diversas maneras en su obra, siendo siempre, en cada una de estas formas, un acicate que estimula el pensamiento y la acción ${ }^{10}$. Para él alteridad es sinónimo de diferencia. Y la diferencia, aquello ajeno que existe fuera de cada sujeto, es la única vía de apertura del mismo a la realidad. Sólo a través de lo extraño, de lo extranjero, pueden cada hombre y mujer tomar conciencia de su propio ser, pues para las personas «la relación es el lugar existencial»" ${ }^{11}$. Por ello, la alteri-

[7] Giard, L.: «Par quoi...» cit., pp. 12 s.

[8] Certeau, M. de: La prisecit., p. 46.

[9] Véase, por poner solo un ejemplo, Buber, M. op. cit.

[10] Aunque es algo que atraviesa todos sus escritos, quizás la obra más recomendable para ampliar el concepto certeauniano de alteridad sea Certeau, M. de: L'étrangercit., desgraciadamente aún sin traducción castellana.

[11] Certeau, M. de: El estallido cit., p. 33. Hans Blumenberg lo ha expresado certeramente: «Los distintos accesos antropológicos a la retórica convergen en una constatación descriptiva

Thémata. Revista de Filosofía №53 (2016) pp.: 195-218. 
dad no solo es un concepto político, sino también epistémico ${ }^{12}$, puesto que nuestro conocimiento del mundo está siempre mediado por la presencia de los otros.

Si para Certeau esta apertura a la realidad a través de los otros es algo constitutivo de la realidad humana, la política vista desde el prisma de la alteridad se sustenta fundamentalmente en la idea de que la vida común está basada en la presencia del otro y de la interacción con él ${ }^{13}$. Y aún más, en la convicción de que esta interacción no solo es necesaria, sino que es positiva y deseable. Aunque algo más adelante se analizará cómo nuestro autor tiene en cuenta los aspectos conflictivos de esta relación, es importante aclarar aquí que cualquier interpretación que reduzca al otro a ser solo un contrario se aleja diametralmente de la postura certeauniana. El otro es imprescindible, pero no porque la realidad se constituya en una dicotomía amigo-enemigo, como en Carl Schmitt y las teorías que derivan de su obra. En ellas, el otro, por su condición de némesis, viene a ser sólo una imagen especular de uno mismo con la que no se produce un intercambio real. Para Certeau, radicalmente en contra de esta postura, tanto «en la práctica como en la teoría, el diferente no es nunca el contrario ${ }^{14}$.

En sus escritos la necesidad del otro es perentoria. "No sin» es la expresión heideggeriana que utilizará para expresar esa necesidad del otro, pues es precisamente la convicción de que no es posible una vida sin el otro la que da realidad a la vida común ${ }^{15}$. La presencia del otro, la capacidad de recibirle y con él lo que aporta de distinto a la convivencia, se convierte así en la clave de bóveda de la política. Y esto por dos motivos que Certeau explica valiéndose de las herramientas de la lingüística, ya que «la alteridad reaparece siempre, y fundamentalmente, en la naturaleza misma del lenguaje» ${ }^{16}$.

El primer motivo es relativo a las personas en tanto que grupo. La interacción con los otros es el marco en que se produce la interlocución

central: el ser humano no tiene ninguna relación inmediata, puramente "interior", consigo mismo. Su autocomprensión tiene la estructura de la "autoexterioridad"», Las realidades cit., p. 141; «El ser humano se comprende a sí mismo yendo más allá de sí mismo, sólo a través de lo que él no es», p. 142.

[12] Certeau, M. de: L'écriturecit., pp. 61-65.

[13] Certeau, M. de: L'étrangercit., p. 9.

[14] Certeau, M. de: La prisecit., p. 77.

[15] Esta expresión aparece en las primeras páginas de dos de las principales obras de Certeau, Certeau, M. de: L'étrangercit., p. 9; La fable cit., p. 9. A pesar de la claridad con que Certeau vincula esta expresión a su origen en Martin Heidegger, Joseph Moingt ha puesto en cuestión la coherencia del uso de este término en Certeau y el filósofo alemán, Moingt, J.: op. cit., p. 585.

[16] Certeau, M. de: Histoirecit., p. 169. Para profundizar en la perspectiva lingüística de

Thémata. Revista de Filosofía Nº53 (2016) pp.: 195-218. 
entre emisores y receptores de mensajes. Y esto de tal forma que si cambia dicha interacción cambia también el marco de interlocución, lo que afecta a las posibilidades de comprensión entre los diferentes interlocutores. Luego cada grupo humano, cada unidad política, configura un espacio conversacional en el que se emiten y reciben mensajes que, colocados en otro marco, podrían significar cosas distintas. El conjunto de las relaciones que las personas establecen con sus otros concretos (habitantes de un tiempo y un lugar comunes), lo que Certeau llama la «topografía contractual de los interlocutores» ${ }^{17}$, es así la clave de la política. Al cambiar los elementos que forman estas relaciones la comunicación se altera, generando así un espacio de convivencia diferente. De esta forma, la diferencia que suponen los otros es la tierra sobre la que la comunicación interpersonal puede surgir, permitiendo el desarrollo de una realidad política común.

El segundo motivo, de tipo individual, es que la diferencia de cada otro es preciosa. No se trata ya solo de afirmar la necesidad de vivir en un marco social en el que se permitan y se cultiven las diferencias para poder llevar una existencia verdaderamente humana. Según nuestro autor también la particular divergencia de cada persona (por humilde que sea) es valorable en sí misma, porque presta al conjunto algo distinto de lo que pueden aportar los demás. Subrayando el valor de los sonidos más sencillos de la sinfonía social, Certeau valora y acoge con cariño las pequeñas diferencias cotidianas.

Obsesionado por este rumor extranjero, debo reconocer que ningún texto ni institución podrá jamás «ocupar» el lugar donde se eleva el rumor de las máquinas, las cocinas, de los mil ruidos de una actividad creadora. ${ }^{18}$

La relevancia de estos detalles se entiende mejor si tomamos a la sociedad entera por un acto de comunicación. En ella todo sujeto, en cuanto que término que forma parte de la significación global de la sociedad, es portador de un significado limitado. Significado que no puede expresarse completamente, ni puede ser comprendido de forma adecuada, más que en relación con el significado que le falta y que proviene de los otros. Del mismo modo que el significado latente de una palabra no encuentra su desarrollo más que en el encuentro con el resto de la frase en que se enmarca, así cada sociedad es un marco lingüístico cuyas diferencias son, de algún modo, las reglas que permiten comprender un discurso. Y cada individuo

Certeau sobre esta cuestión, Certeau, M. de: L'écriturecit., pp. 284-335. y La possessioncit., pp. 419-423.

[17] Certeau, M. de: L'Absent cit., p.7 n. 1.

[18] Certeau, M. de: La culturecit, pp. $212 \mathrm{s.}$

Thémata. Revista de Filosofía No53 (2016) pp.: 195-218. 
es, dentro de ese marco, un término preñado de significados que solo pueden comprenderse en relación con otros colindantes.

Por otra parte, la alteridad no está siempre fuera de uno mismo, como ha mostrado a Certeau el estudio paciente del psicoanálisis. De ahí que la noción certeauniana de alteridad esté en íntima trabazón con la importancia atribuida por el psicoanálisis a lo desconocido de cada sujeto en sí mismo, al extranjero interior del que surgen las luces que han de permitir un verdadero conocimiento de sí. La validez dada por Certeau al recurso al inconsciente como método heurístico y terapéutico le permite la exploración de las zonas ocultas de la vida social, algo que hace con brillantez. Al mismo tiempo, y esto es más relevante aún, convierte al otro (también al otro interior) en alguien insustituible por lo que tiene precisamente de diferente. De esta manera, convencido de que «los otros son nuestros verdaderos viajes» ${ }^{19}$, Michel de Certeau asume la búsqueda y acogida del otro como su misión política fundamental.

\subsection{Polemología}

En segundo lugar, la concepción política de Certeau tiene una vertiente polemológica ${ }^{20}$. Esta consiste en la toma de conciencia de la inevitabilidad de las tensiones en la convivencia, que surge de "una concepción política del actuar y de las relaciones no igualitarias entre un poder y sus sujetos ${ }^{21}$. Asimismo, implica el alejamiento, a pesar de su sincero elogio de la alteridad, de construcciones edulcoradas y utópicas sobre la condición humana en su dimensión social. «La política no asegura la felicidad ni da el sentido a las cosas. Ella crea o rechaza las condiciones de posibilidad. Prohibe o permite: hace posible o imposible» ${ }^{22}$.

Es muy dudoso, por lo que sabemos del ambiente de su infancia, que Certeau percibiera el entorno social en que nació y creció como aquella Arcadia feliz de la que hablara Schopenhauer ${ }^{23}$. De todas formas, aunque así hubiera sido, el tiempo, su experiencia y sus lecturas le hicieron consciente de que la realidad no se acomoda a un planteamiento dulce e ingenuo, más allá del tono vital de cada uno. Hay una objetividad conflictiva y

[19] Certeau, M. de: La faiblesse cit., p. 27.

[20] Certeau, M. de: L'invention cit., pp. XLIV, 57, 63. En este sentido se observa una notable coincidencia con Unamuno (op.cit., p. 283) y con Peter Sloterdijk (op. cit., p. 57).

[21] Giard, L.: «Histoire...» cit., p. XV.

[22] Certeau, M. de: La culture cit., p. 187.

[23] Schopenhauer, A.: op. cit., p. 29.

Thémata. Revista de Filosofía №53 (2016) pp.: 195-218. 
no se trata ante ella de ser pesimista o de no serlo, sino de hacerse cargo de una convivencia social que está constitutivamente marcada por el conflicto.

Las relaciones entre grupos son interacciones conflictivas. Imposible, por tanto, suscribir las visiones idealistas que supondrían posible una reglamentación de los conflictos por la vía de la "comprensión" mutua. ${ }^{24}$

El profundo estudio consagrado por Certeau a los aspectos más sencillos de la vida cotidiana le permitió recoger pruebas más que suficientes para apoyar esta tesis. Son ellas las que le llevan a afirmar que toda la realidad social tiene un aspecto polémico que posibilita identificar cómo «la práctica cotidiana es relativa a relaciones de fuerza que estructuran tanto el campo social como el campo del saber» ${ }^{25}$. Esta constatación debe llevar al pensador de lo social a «un análisis polemológico de la cultura» ${ }^{26}$, que tenga especialmente en cuenta a los eslabones más débiles de la cadena social: los consumidores.

La polemología certeauniana ofrece una vez más una perspectiva cercana a aquella que expresara Freud al dar cuenta de su teoría de las pulsiones:

No cuenta aquí una oposición entre teoría optimista y pesimista de la vida; sólo la acción eficaz conjugada y contraria de las dos pulsiones primordiales, Eros y pulsión de muerte, explica la variedad de los fenómenos vitales, nunca una sola de ellas. ${ }^{27}$

Desde este punto de vista, asumido con matices por Certeau, un principio de contradicción vertebra la realidad: la ley del conflicto ${ }^{28}$. Toda la convivencia humana está relación con esta ley y aunque Certeau haya

[24] Certeau, M. de: "L’actif..." cit., p. 160. Esta condición ambivalente de la convivencia ha sido señalada, una vez más, por Ortega, cuando afirma que «siendo al hombre imposible entenderse con sus semejantes, estando condenado a radical soledad, se extenúa en sus esfuerzos para llegar al prójimo». Ortega y Gasset, J. La rebelión cit., p. 10; y más adelante «esta convivencia tomaba indiferentemente aspecto pacífico y combativo», p. 14.

[25] Certeau, M. de; Giard, L. y Mayol, P.: L'invention du quotidien. 2. cit., pp. 2, 358.

[26] Certeau, M. de: L'invention cit., p. XLIV.

[27] Freud, S.: op. cit., p. 245.

[28] Certeau, M. de: L'étranger cit., pp. 21-43. "La guerra [...] es una función natural del organismo humano», Ortega y Gasset, J. España cit., p. 35. 
abogado con entusiasmo por el otro como elemento esencial de la propia vida, no deja de reconocer la dificultad que entraña esta convivencia.

El otro es peligroso. Hiere al que no se defiende. Fundamentalmente es el rostro de la muerte [...] La experiencia del otro es temible, análoga a la del Dios de la Biblia, al que no cabe encontrar sin morir. No puede ser tratada con el sentimentalismo o la ideología de esos "diálogos" que, de hecho, niegan al otro y buscan finalmente envolverlo, seducirlo, neutralizarlo, captarlo o huirlo. ${ }^{29}$

Pero para Certeau, igual que la búsqueda de Dios, la búsqueda del otro es una hermosa condena. Para él la conflictividad inherente al encuentro con el otro no es negativa y, de hecho, llegará a afirmar que es la fuerza que permite la construcción de un cuerpo social, articulando las distintas voluntades presentes en dicho cuerpo ${ }^{30}$. Sin embargo, Certeau insiste en que, en muchas ocasiones, el mundo occidental no asume con claridad esta permanente colisión de fuerzas movidas por intereses enfrentados.

En el momento en que, por su trabajo, una acción comienza a modificar los equilibrios de fuerzas, es interrumpida por la represión que organizan los poderes establecidos [...] En las sociedades llamadas civilizadas no se espera que el conflicto aparezca. Se le previene. ${ }^{31}$

Como todo buen freudiano, Certeau denuncia este afán por esconder la verdad. La ley del conflicto, siendo real como es, pierde gran parte de su potencial destructor si es declarada ante uno mismo y ante los demás. Su ocultación o disimulo no augura nada bueno para un grupo o sociedad. Aunque Certeau es consciente de la dificultad que supone, pues «toda organización supone una represión ${ }^{32}$, invita a abandonar esta inconsciencia autoimpuesta. Y es que es precisamente la asunción de la ley del conflicto la que permite iniciar los trabajos necesarios para superarla ${ }^{33}$. Pues la humanidad no está condenada a vivir en un mundo permanentemente en

[29] Certeau, M. de: El estallido cit., pp. $37 \mathrm{~s}$.

[30] "Desde los Derechos del Hombre hasta las vacaciones pagadas no ha habido jamás una innovación cultural sin conflictos sociales y sin victorias políticas”, Certeau, M. de: La culture cit., p. 187; ver también "L'actif..." cit.

[31] Certeau, M. de: La culture cit., pp- 189 s.

[32] Ibidem, p. 71.

[33] Se ha publicado recientemente un magnífico estudio sobre los conflictos por el poder en la historia española que hace suyo este objetivo y que apoya la tesis polemológica de Certeau. Cfr. Villacañas, J.L.: op. cit. 
guerra. En el siguiente texto esta convicción queda recogida con claridad, a la vez que se introduce una reflexión sobre la violencia a la que se prestará atención enseguida.

Una cosa es constatar, en el conflicto, un elemento imposible de eliminar de la experiencia humana y, en el actual aumento de la violencia, una reivindicación tan esencial que renunciar a ella equivaldría a perder el derecho y el placer de existir (hay causas que valen más que la vida); y otra hacer de la violencia una ley [...] que rebajaría la voluntad de llegar a ser hombres juntos a no ser más que la "ley" bestial (o natural) de un struggleforlife. ${ }^{34}$

Como hemos visto, en Certeau conflicto y violencia no son la misma cosa, aunque ambas forman parte de su noción polemológica de sociedad. No obstante, las afirmaciones de nuestro autor respecto a la violencia pueden provocar muchas preguntas en el lector. Sin pretender dar una visión acabada del pensamiento de Certeau sobre la esta cuestión, sí creo oportuno hacer algunas consideraciones que ayuden a ver cómo se articula en el conjunto de una concepción conflictiva de lo social ${ }^{35}$.

En primer lugar, es destacable que cuando Certeau se enfrenta al estudio de circunstancias en las que está presente la violencia (Mayo del 68, conflictos sociopolíticos de América Latina durante la década de 1970, etc.), no cae en la fácil tentación de desacreditarla venga de donde venga. Más bien tiende a hacer afirmaciones que abren una puerta a un uso adecuado o justo de la violencia. Las siguientes proceden de La culture aupluriel: «la violencia es más el síntoma que la respuesta» "36; «lo que es verdad, es que la violencia indica un cambio necesario» ${ }^{37}$; «[...]la violencia de la que la mayoría de estudiantes desaprueba las formas y las justificaciones ideológicas, pero reconoce el sentido» ${ }^{38}$.

En segundo lugar, esta aceptación de la violencia (que no debe confundirse con su apología o el deseo de que esta crezca), favorecida por su formación como historiador, facilita que Certeau pueda dar cuenta de realidades que otros pensadores se empeñan en descartar o justificar con subterfugios o excusas más o menos fundamentadas. Por ejemplo, ante la evolución histórica de la aparición y constitución de los distintos estados y

[34] Ibidem, p. 26.

[35] Considero aquí muy interesante la referencia a Arendt, H.: op. cit. Certeau cita a Arendt con aprobación en Histoirecit., p. 147; y en La fable cit., p. 277.

[36] Certeau, M. de: La culture cit., p. 100 n. 19.

[37] Ibidem, p. 81.

[38] Certeau, M. de: La culture cit., p. 98.

Thémata. Revista de Filosofía $\mathrm{N}^{\circ} 53$ (2016) pp.: 195-218. 
regímenes políticos, puede afirmar que «como piensa Hobbes, toda legitimidad toma su origen en la ilegitimidad de una violencia» ${ }^{39}$.

Reconocer la existencia de la violencia como un hecho constante modifica la mirada del pensador respecto a los hechos sociales que le son contemporáneos. Al observarlos, esta nueva perspectiva le permitirá no dejarse engañar por la propaganda de los poderes que aspiran a mantener un status quo, que pretende demonizar todo intento serio de cambio de la organización social. Los intereses de los grupos que no ostentan el poder, reprimidos por la maquinaria del estado, antes o después tenderán a emerger desde las alcantarillas, en muchas ocasiones con un despliegue de expresiones más o menos violentas. Los poderosos, sean quienes sean, se verán entonces autorizados a contestar con medios tanto o más violentos que los de los oprimidos. Justificada de mil maneras, esta violencia del poder aparecerá invariablemente para proteger «la propiedad que funda la violencia» ${ }^{40}$.

De esta forma, para Certeau, en el conjunto de las interacciones sociales «el acto violento señala la irrupción de un grupo» ${ }^{41}$. La colisión entre facciones se anuncia entonces como algo inevitable, en parte como respuesta a la situación de represión y de desigualdad de poderes a que se ha hecho referencia antes, y en parte por una necesidad interna a cada colectivo social, ya que «el rechazo del "partido" adverso es el modo sobre el que se determina un grupo» ${ }^{42}$.

Por último, pero no menos importante, hay que señalar que es la propia experiencia vital la que lleva a Certeau a permitirse estos razonamientos. Es en el ámbito espiritual donde nuestro autor va descubriendo que la violencia está ahí como una realidad, más allá de la valoración moral que se haga sobre su utilización en esta o aquella circunstancia. Una expresión de su maestro en la distancia de los siglos, Jean-Joseph Surin, lo resume con acierto recordando toda una tradición ascética que atraviesa el conjunto de las religiones y las filosofías del mundo: «Todo hábito del bien, al principio, necesita de la violencia» ${ }^{43}$. En Certeau, el desconcertante reconocimiento de la propia violencia le llevará a afirmar que «la violencia no

[39] Certeau, M. de: Le lieu cit., p. 211.

[40] Certeau, M. de: La fable cit., p. 62.

[41] Certeau, M. de: La culture cit., pp. 80 s.

[42] Certeau, M. de: Le lieucit., p. 181.

[43] Certeau, M. de: «Introduction» cit., p. 28.

Thémata. Revista de Filosofía №53 (2016) pp.: 195-218. 
es desde un principio una materia de reflexión, ni un objeto que se ofrece a un observador. Está inscrita en el lugar desde donde hablo. Lo define» ${ }^{44}$.

Desde esta posición final se hace posible responder a la pregunta que nos hacíamos al principio de esta sección acerca de qué fuera la política para Certeau. Encuentro y conflicto son las dos palabras claves para ello, clarificando con su presencia la noción certeauniana de la convivencia social, de la política.

\section{El valor de la institución}

Una vez descrita la forma en que Certeau se sitúa ante la realidad social vista de forma general, es hora de introducirse algo más dentro de esta concepción. Principalmente con el objetivo de entender qué relación existe entre las creencias y esta coexistencia social de seres diferentes en conflicto. Para ello es difícil sustraerse al interés que suscita en Certeau un sujeto social concreto, que desempeña un papel protagonista en sus textos: la institución ${ }^{45}$.

En esta sección se muestra cómo Certeau penetra en el oscuro interior de las instituciones e ilumina sus mecanismos de funcionamiento, llegando a una conclusión clara: las instituciones manifiestan la paradójica realidad de ser corruptas y necesarias a un mismo tiempo.

\subsection{Necesidad de la institución: la producción de un sentido creíble}

Antes de comenzar a desgranar los distintos aspectos de las instituciones que Certeau nos muestra en su obra, puede ser oportuno aclarar que en los textos que se irán citando en adelante, autoridad e institución han de considerarse términos prácticamente sinónimos ${ }^{46}$.

La amplitud que entraña el examen certeauniano de la institución es impresionante. No hay resquicio donde no entre su análisis, ni pequeña

[44] Certeau, M. de: La culture cit., p. 73.

[45] La obra más importante de cara a conocer el análisis de las instituciones en Certeau es Giard, L.; Martin, H. y Revel, J.: op. cit.

[46] La definición certeauniana de autoridad puede encontrarse en La faiblesse cit., p. 89 n. 1. Este texto, titulado "Autoridades cristianas y estructuras sociales", es esencial a todas luces por su claridad y profundidad. Publicado originalmente en Études entre 1969 y 1970, este texto se englobó dentro de un dossier en el que también participaron los jesuitas Henri de Lavalette y Louis Beirnaert (fallecidos en abril y noviembre de 1985, solo unos meses antes que Certeau, y con los que comparte sepultura en el cementerio parisino de Vaugirard). Giard, L.: "CherchantDieu" cit., p. 21.

Thémata. Revista de Filosofía №53 (2016) pp.: 195-218. 
autoridad doméstica cuyo papel, cuya dinámica, no esté dispuesto a estudiar. Por otra parte, no es solo este cuidadoso catálogo de las variedades de la autoridad lo que da amplitud a la mirada certeauniana. Lo hacen también las consecuencias que dicho análisis puede tener para el pensador y su entorno. En opinión de Certeau ya por el mismo hecho de cuestionarnos en este sentido estamos poniendo patas arriba la configuración de nuestra sociedad, porque «la pregunta sobre las autoridades entraña un examen nuevo de nuestras sociedades contemporáneas» ${ }^{47}$.

Partamos ahora de una afirmación certeauniana básica para seguir explorando el mundo de la institución. «La vida social exige la creencia [...] que se articula sobre los supuestos saberes garantizados por las instituciones» ${ }^{48}$. Esta premisa (razón principal por la que nuestro autor afirma que las instituciones son necesarias) describe y resume el modo en que la creencia afecta a la dimensión epistémica y a la dimensión social de la antropología; consagra la necesidad de la institución, al mismo tiempo que denuncia la falacia de su pretendido poder, que se basa en "supuestos saberes».

Pero, ¿por qué es necesaria la existencia de estos supuestos saberes que garantiza la institución y que sirven de sostén a la creencia? Esencialmente, nos enseña Certeau, porque son una pieza fundamental para que sea posible articular un sentido. "Las autoridades permiten a cada uno articular su relación con los otros con su relación con respecto de una verdad $\rangle^{49}$. Es precisamente en esa articulación entre lo epistémico y lo social donde las autoridades, a las que Certeau llama también «instituciones de sentido» ${ }^{50}$, se hacen imprescindibles al representar «una credibilidad $»^{51}$, siendo así que «la institución no es más que aquello que permite a la fe una objetividad social» $»^{52}$.

Las instituciones son las depositarias temporales de una energía creyente que surge, sin dueño, de cada sociedad, aglutinando así a sus integrantes en torno a un discurso y una práctica compartida. Y lo son

[47] Certeau, M. de: La faiblesse cit., p. 89 n. 1.

[48] Certeau, M. de: Histoire cit., p. 136.

[49] Certeau, M. de: La culture cit., p. 19.

[50] Certeau, M. de: La faiblesse cit., p. 187 n. 1.

[51] Certeau, M. de: La culture cit., p. 19.

[52] Certeau, M. de: La faiblesse cit., p. 299. Odo Marquard dirá que las instituciones tienen como función reducir «el lastre de la acción a una dimensión apropiada a la capacidad de actuación humana", es decir, que adecúan lo que las personas hacen a lo que de verdad pueden hacer. Marquard, O.: Adiós cit., p. 90. «Donde el mundo, debido a la aceleración del cambio, se vuelve cada vez más complejo, hace falta cada vez más la reducción de complejidad... Hace falta algún tipo de confianza. Si no hay más remedio, se inventan los garantes de la confianza», Apología cit., p. 98.

Thémata. Revista de Filosofía №53 (2016) pp.: 195-218. 
porque la credibilidad que ofrecen solo puede ser provisional al basarse en saberes que necesariamente son parciales. Pasando el tiempo esta credibilidad se resquebrajará cuando, buscando su persistencia y la ampliación de su dominio sobre una sociedad, la institución vaya falazmente absolutizando aquellos saberes y poniéndose a sí misma en el lugar de la energía de la fe que la hizo nacer.

Por ello, el aspecto físico, puramente organizacional de las instituciones, tendrá un papel esencial en el desarrollo, mantenimiento y fractura de la credibilidad de la que son depositarias, favoreciendo o dificultando la adhesión de la creencia a sus discursos. Debido a que «estructuras sociales y estructuras de sentido se sostienen mutuamente» ${ }^{53}$, este aspecto organizacional estará estrechamente relacionado con la forma en que una sociedad configure el papel de sus instituciones, porque además «cada institución particular se apoya sobre otras, en una red que constituye "la tela de araña del creer" $»^{54}$.

Por otra parte, si las autoridades son la vía de objetivación social de una fe, son también, al mismo tiempo y principalmente, productoras de discursos. Estos son sus propuestas de sentido y el cauce a través del que captan y canalizan la energía creyente de una sociedad. Toda institución ha de producir un discurso creíble para poder existir. Certeau señalará, haciendo referencia a este carácter logocéntrico de las autoridades, que «la retórica es institucional e institucionalizante, tanto como la institución es retorizante $»^{55}$.

El discurso de cada institución, su relato, es su propuesta de sentido para un tiempo y un lugar. Más o menos ambicioso y completo en su pretensión de explicar un mundo, siempre tiene por característica la voluntad de generar un efecto en sus receptores, pues «la institución tiene fundamentalmente por función hacer creer en una adecuación del discurso y la realidad, dando su discurso como la ley de la realidad» ${ }^{56}$. Adhesión o rechazo, movimiento a favor o en contra, el discurso de la institución no busca un resultado exclusivamente estético, sino crear una acción. Acción que se presenta como la respuesta eficaz de una sociedad a las encrucijadas que un mundo concreto le ofrece y que el discurso institucional presume describir y descifrar adecuadamente. «Toda autoridad se funda, en

[53] Certeau, M. de: La faiblesse cit., p. 275.

[54] Certeau, M. de: Histoire cit., p. 132.

[55] Certeau, M. de: Le lieu cit., p. 131. «Donde faltan las evidencias, la retórica crea instituciones», Blumenberg, H.:Las realidades cit., p. 121.

[56] Certeau, M. de: Histoire cit., p. 132.

Thémata. Revista de Filosofía $\mathrm{N}^{\circ} 53$ (2016) pp.: 195-218. 
efecto, sobre lo real que supuestamente declara. Siempre es en nombre de algo real que se "hace caminar" a los creyentes y que se les produce» ${ }^{57}$.

Será por tanto, la aceptación de la verdad del discurso de la institución y la puesta en práctica de las directrices que emanan de éste, y que ella consigna, las que describan la adhesión a una autoridad. El discurso de la institución, aceptado por la fe, se convierte así en una especie de profecía autocumplida, pues hace que se haga verdad aquello que (con más o menos rigor) anuncia como cierto. «El relato es eficaz. Pretendiendo narrar lo real, lo fabrica. Es performativo. Hace creíble lo que dice y hace actuar en consecuencia. Produciendo creyentes, produce practicantes ${ }^{58}$.

De esta forma, desde una perspectiva certeauniana, se produce la articulación entre lo epistémico y lo social en el vértice en que se convierte la institución. En ella se lleva a cabo una secuencia esencial para la vida humana, mil veces repetida y corregida a lo largo de la historia: una descripción de la realidad, un programa de acción inspirado en la misma y la puesta en práctica de dicho programa en compañía de otros.

No hay que olvidar, por tanto, que en su origen el discurso de la institución se presenta como una oferta de sentido que abre las puertas a una acción, pues «lo real contado dicta interminablemente lo que hace falta creer y lo que hace falta hacer $\aleph^{59}$. Sus adherentes, los creyentes de la institución, lo seguirán sobre todo en la medida en que sea creíble, ya que «una credibilidad del discurso es desde un primer momento lo que hace andar a los creyentes. Produce practicantes. Hacer creer es hacer hacer» ${ }^{60}$.

De ahí que la cerrazón de las élites dirigentes de cada institución en defender sus propios intereses se convierta en una bomba de relojería para la credibilidad de la misma. El afán por la interpretación del relato de la institución según un sentido literal necesariamente irá impidiendo a nuevos creyentes la comprensión del mismo, al ir cambiando los elementos contextuales que permiten entender un discurso en un tiempo y un lugar dados. La ruptura de la adhesión se cierne entonces sobre las autoridades como un cuervo sombrío.

Al mirar su propia situación social desde una perspectiva crítica, nuestro autor dará cuenta en sus textos de la orfandad de sentido que supone para una sociedad la caída de los discursos de las instituciones referentes, los grandes relatos que en cada época sostienen una existencia común. En lo referente al mundo en que vivió, Certeau señalará la ausencia definitiva de discursos capaces de proveer de un sentido creíble

[57] Ibídem, p. 57.

[58] Ibídem, p. 63.

[59] Certeau, M. de: Linvention cit., p. 271.

[60] Ibídem, p. 218.

Thémata. Revista de Filosofía Nº53 (2016) pp.: 195-218. 
invocando una autoridad superior y lejana a la propia sociedad. En este sentido, afirmará que en ausencia de instituciones fuertes la garantía de credibilidad son los otros.

La creencia ya no descansa en una alteridad invisible oculta tras los signos, sino sobre lo que otros grupos, otros campos, u otras disciplinas supuestamente son. Lo «real» es lo que, en cada sitio, la referencia al otro hace creer. ${ }^{61}$

Éste es el motivo de que, en nuestras sociedades, crezca la importancia de las prácticas en tanto que identificadores de la pertenencia a un grupo (a una institución), mientras que va disminuyendo en tanto que expresión de la adhesión a una verdad. Desde la convulsa época de la Reforma protestante hasta hoy, «la producción de lazos sociales sustituye al reconocimiento de verdades establecidas ${ }^{62}$. Poco a poco se pierde la mentalidad sacramental de tiempos anteriores, que viera en la realización de tal o cual práctica la ocasión de ponerse en contacto con una realidad trascendente a la cotidianidad de las cosas. Es sustituida por una nueva mentalidad, a la que se podría llamar retorizante ${ }^{63}$, que ya no busca expresar una verdad sino emitir un mensaje que, dentro de un texto más amplio, cumpla con la parte que le toca para conseguir un objetivo.

\subsection{Cómo la institución se hace depositaria del creer: la adhesión}

Tras lo expuesto en la sección anterior podemos dar por cierto que la principal misión de las instituciones es ofrecer un sentido y que la creencia es la energía que las personas depositan en ellas, a modo de inversión, a cambio de admitir como verdadero el discurso ofrecido. Se establece así entre institución y sociedad una relación de intercambio cuyo eje es la creencia y que es del máximo interés para Certeau. Tanto es así que (como ha afirmado Luce Giard a colación del análisis certeauniano de los acontecimientos de Mayo del 68), el estudio de la dinámica de esta relación entre creencia e institución es una de las líneas centrales del pensamiento certeauniano. Nuestro autor «tras este episodio [Mayo 68] vuelve a menudo

[61] Ibídem, p. 273.

[62] Certeau, M. de: Le lieu cit., p. 131.

[63] Para ampliar la idea certeauniana de «sociedad recitada», basada en el creer porque otro cree, Certeau, M. de: L`invention cit., pp. 273 ss.

Thémata. Revista de Filosofía №53 (2016) pp.: 195-218. 
bajo ángulos diversos sobre el lazo que une a los "creyentes" a una institución (del creer, del saber o del actuar)» ${ }^{64}$.

Uno de los términos esenciales que aparecen como fruto de este estudio es el de adhesión, que viene a ser el término central, el nexo de unión, de la ecuación que pone en juego por un lado al discurso de la institución y por otro a las creencias. Como dirá Certeau con contundencia «toda autoridad reposa sobre una adhesión» ${ }^{65}$. La atención prestada a este concepto es, en mi opinión, uno de los hechos diferenciales (quizás el principal) de los estudios certeaunianos acerca de «las autoridades sobre las que se adosa una creencia» ${ }^{66}$.

Dándole un tono dinámico que se centra en el movimiento entre creer y no creer, la adhesión distingue la perspectiva de Certeau de aquellas centradas estrictamente en los elementos organizacionales de las instituciones, por un lado, y de aquellas que estudian las creencias en tanto que concreciones fijas de discursos de sentido, por otro. En Certeau lo que destaca es la intención de captar el modo en que sucede ese sutil y maravilloso acontecimiento por el que, en un tiempo y una sociedad dadas, «las creencias surgen, haciendo posible una elaboración común» ${ }^{67}$.

Respecto a la adhesión creo que pueden señalarse tres ideas básicas, relativas a la frecuencia de su aparición, a su tipología y a lo necesario de su presencia para que la institución exista.

En primer lugar, ha de afirmarse que la interacción de tipo comercial que da como resultado la adhesión (discurso ofrecido-creencia que lo acepta), no es algo anecdótico o casual dentro del funcionamiento habitual de los grupos humanos. Antes bien hay que dar cuenta del hecho de que existe una disposición humana a formar parte de las instituciones ${ }^{68}$. Y esto no solo en el ámbito de la alta política, ya que las autoridades no son exclusivas de un campo vital determinado. También los aspectos menores de la existencia (la vida familiar, laboral o del vecindario) necesitan de instituciones que permitan la canalización de la energía creyente. Así, «la vida cotidiana, como la política o la filosofía, conoce estas autoridades que ofrecen campos nuevos al pensamiento y la existencia colectiva ${ }^{69}$.

En segundo lugar, puede afirmarse con Certeau que hay varios tipos de adhesión dentro del conjunto de personas que participan de la vida

[64] Giard, L.: «Un chemin...» cit., pp. 24 s.

[65] Certeau, M. de: La culture cit., p. 29.

[66] Certeau, M. de: Le lieu cit., p. 202.

[67] Certeau, M. de: La culture cit., p. 27.

[68] Para una aproximación psicoanalítica a esta cuestión puede verse el estudio dedicado por Certeau al escrito de Freud sobre el pintor C. Haiztmann, Certeau, M. de: L'écriturecit., pp. 339-364.

[69] Certeau, M. de: La culture cit., p. 29.

Thémata. Revista de Filosofía №53 (2016) pp.: 195-218. 
de la institución, pudiendo darse una adhesión verdadera, pero también una falsa adhesión. «Una subversión se insinúa bajo la forma de participación. Es la resistencia compatible con la debilidad» ${ }^{70}$.Si bien la adhesión verdadera es más fácil de comprender y a menudo se la da por supuesta, Certeau tiene siempre en cuenta que entre los miembros de un cuerpo social no están solo aquellos que mantienen a través de sus actos la creencia en los valores que sostienen dicho cuerpo, sino también aquellos otros que han perdido esa creencia (depositada ahora en otros lugares). Aunque los primeros (los fuertes) suelen ostentar un mayor grado de protagonismo dentro de la institución, ha de contarse también con los segundos (los débiles), a menudo silenciosos y semiocultos. En todas y cada una de las ocasiones en que se analiza el funcionamiento de una institución, sea del tipo que sea, se encontrará el pensador sagaz con quienes afirman mantener las convicciones institucionales, pero lo hacen únicamente de forma táctica. La existencia de esta falsa adhesión en el seno de cualquier sistema institucional puede explicar por qué un pequeño gesto de rechazo a la institución, por aparentemente pobre y aislado que pueda parecer, es capaz de dar lugar a un movimiento social de contestación frente a la autoridad de una enorme amplitud.

Esta idea nos permite llegar al tercer aspecto a señalar respecto de la adhesión vista desde un punto de vista certeauniano: el hecho de que las instituciones no pueden sobrevivir más que a partir de la adhesión, del depósito de las creencias recibidas. Es interesante en este sentido la advertencia que Certeau hace a aquellos que pretenden ver con facilidad cuándo una institución ha perdido la credibilidad para sus adherentes. Se ha distinguido antes entre adhesión verdadera y falsa, así como entre débiles y fuertes creyentes. Pues bien, no siempre el que aparenta debilidad ejerce una falsa adhesión ni siempre la adhesión del fuerte es verdadera. También puede ocurrir, como así es de hecho en mil ocasiones, que exista una adhesión social invisible pero constante respecto de esta o aquella autoridad.

Por ello Certeau avisa de que, a pesar de que con frecuencia se pronostique el fin de una institución al echarse de menos la presencia de creyentes fuertes, esta percepción puede llevar a engaño. No solo los fuertes sostienen una autoridad con sus creencias, sino que más abajo, en la invisibilidad de los planos inferiores que ocupan los creyentes desapercibidos,

[70] Certeau, M. de: La prise cit., p. 142.

Thémata. Revista de Filosofía Nº53 (2016) pp.: 195-218. 
puede seguir existiendo un depósito de fe. Certeau avisará a sus lectores de que

a menudo tácito, oculto en el fondo de convicciones apenas formuladas (tenues por evidentes) o durante un tiempo reconocidas en las representaciones que precisan el contenido, un consensus funda por sí solo un sistema de autoridades. ${ }^{71}$

En uno u otro sentido, sea como apoyo o como rechazo de la institución, la presencia o la falta de una adhesión real a su discurso no se caracterizan precisamente por su estridencia, sino más bien por su carácter desapercibido y sutil.

El silencio nunca es inerte; masivo, da su peso a los enunciados de la autoridad; pero si los abandona, les retira al mismo tiempo su crédito y, dejando flotar las formulaciones abandonadas, ya demasiado estrechas o demasiado antiguas, se cambia en la palabra que contesta o en otro silencio que es alejamiento. ${ }^{72}$

\subsection{El poder, vía de corrupción}

Vistos ya el por qué de toda institución (ofrecer un sentido) y el modo en que la adhesión permite que se canalice la energía del creer (aceptando el sentido propuesto y sus prácticas asociadas), prestemos atención ahora a la dinámica histórica de la institución. En la dimensión temporal de una autoridad, es decir, en el tiempo que abarca desde el momento de su fundación hasta el de su desaparición, participan numerosos factores. Sin embargo, no hay ninguno que tenga tanta influencia como el poder. «Tiene “autoridad" lo que es creíble; tiene poder lo que se impone» ${ }^{73}$.

En toda institución, sometida por su condición humana a las exigencias de la historicidad, llega un momento evolutivo en que se confunden y se entremezclan estos dos términos, iniciándose una crisis que podrá llevar a la institución a una refundación o a su extinción. La conjunción inestable entre ambos puede verse puesta en cuestión en cualquiera de sus dos términos y en un sentido creciente o decreciente, es decir, por pérdida o ganancia de autoridad o de poder.

El inicio de esta cohabitación entre autoridad y poder aparece ya en los comienzos de la existencia de la institución. Ella quiere liderar, busca con pasión marcar los cauces de una energía social y por ello, una vez

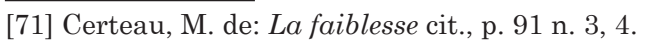

[72] Ídem.

[73] Certeau, M. de: La prise cit., p. 145.

Thémata. Revista de Filosofía Nº53 (2016) pp.: 195-218. 
conseguida la credibilidad que le otorga autoridad, con más o menos rapidez iniciará una senda de imposición de sus planteamientos: el camino del poder. Será el momento en que la institución ponga en marcha los mecanismos a través de los que se garantiza el cumplimiento de las dos funciones que son propias de toda dogmática: «la pretensión de hablar en nombre de algo real» ${ }^{74}$, y la distribución de ese discurso «en elementos organizadores de prácticas, es decir, en "artículos de fe" ${ }^{75}$. Por poner solo un ejemplo de la manera en que pueden concretarse estos mecanismos, en relación al modo en que se ponen en marcha en nuestras sociedades, Certeau señalará que el primer aspecto, el discurso sobre lo real, se realiza en el discurso de los medios de comunicación social; y que el segundo, los artículos de fe, se configura como un catálogo de los productos de consumo ${ }^{76}$.

Tarde más o menos en aparecer, al final el poder tiende a instalarse como la verdadera fuerza motriz de la institución. Situado en esta posición de dominio responderá ante cada iniciativa que sea percibida como una amenaza para su persistencia. De forma pertinaz, el poder se defiende. Primero lo hará con suavidad, a través de los vigilantes de la ortodoxia del discurso, que se enrocan en «los privilegios de la institución para definir el sentido» ${ }^{77}$. Ellos son los defensores de la institución, y su predominio la llevará al triunfo de la burocracia, expresión por excelencia de un poder $\sin$ autoridad ${ }^{78}$. Muchísimos ejemplos de las artimañas de estos defensores atraviesan los textos certeaunianos. Como el de tantos teólogos que reaccionan frente a los místicos, con ataques que parecen surgir de una guerra civil, pues se producen dentro de la misma institución. Es el caso, entre tantos otros, de San Juan de la Cruz, prisionero en Toledo de 1577 a 1578 y «silenciado desde antes de su muerte por la Orden misma de la que ha sido el iniciador» ${ }^{79}$.

Pero si el recurso a las palabras y las amenazas de expulsión no dan resultado, el poder no dudará en ejercer otros modos de defensa, menos civilizados. Peter Sloterdijk ha descrito muy bien como el poder buscará crear una sensación de peligro entre las gentes, lo que desincentiva a los rebeldes y anima a los miedosos a ponerse bajo el paraguas de la institución. De ahí que «el potencial más significativo del poder moderno resida en la capacidad de amenazar, esto es, en la aptitud para mostrar, tanto a

[74] Certeau, M. de: Linvention cit., p. 269.

[75] Ibidem, p. 270.

[76] Esta cuestión es uno de los elementos esenciales de L'invention cit.

[77] Certeau, M. de: La fable cit., p. 396.

[78] Certeau, M. de: La culture cit., p. 76.

[79] Certeau, M. de: La fable cit., p. 181.

Thémata. Revista de Filosofía N53 (2016) pp.: 195-218. 
los enemigos como a los súbditos del señor, el rostro de la muerte» ${ }^{80}$. En esta línea las páginas que Michel de Certeau dedica a la tortura, precisamente en tanto que instrumento del poder, construyen, en mi opinión, su texto más duro: $L_{u d e r}{ }^{81}$. En ellas nos obligará a pensar en la tortura y a considerar el carácter terroríficamente expansivo de su naturaleza, al afirmar que no cesa de desarrollarse ${ }^{82}$.

Esta es la forma en que la institución puede corromperse al traicionar su objetivo esencial, al sustituir su autoridad por poder ${ }^{83}$. Pero esto no es algo que ocurre solo en las instituciones depravadas y perversas (y doy por hecho que no hace falta que sugiera ejemplos al lector), sino incluso en las mejores y más sinceras de ellas.

En las primeras desde el principio es el afán de poder el que mueve a la institución, que solo empuña un discurso sobre lo real como una excusa con la que poder movilizar las creencias o, lo que es más frecuente, con la que camufla el terror con que verdaderamente genera un movimiento entre quienes están en sus garras. En las segundas, lamentablemente, por más vehemente y convencida que fuera la interpretación de lo real que dio lugar a su relato, y por más ejemplo que sus dirigentes diesen y que los adherentes a la institución siguieran como un camino seguro, también antes o después la tentación del poder se hace presente.

Así, a pesar de la necesidad que una sociedad tiene de ellas, las instituciones siempre están en riesgo de terminar defraudando la fe (la energía de las creencias) que se ha depositado en ellas, en la medida en que ganen poder pero pierdan autoridad. Porque la autoridad es algo sutil, una forma casi evanescente de hacerse fundamental para otros. Como dirá Certeau, «la autoridad se presenta con el doble carácter de ser necesaria e inasible ${ }^{84}$.

\subsection{Desafección y abandono}

Como la tentación del poder se hace siempre tan fuerte, la historia de las instituciones suele ser la historia de mil fracasos repetidos. En nuestro tiempo, al plantear cualquier estudio serio sobre las instituciones

[80] Sloterdijk, P.: op. cit., p. 39.

[81] Certeau, M. de: Histoire cit., pp. 219-238.

[82] Ibídem, p. 227.

[83] Certeau señalará a la división de poderes como una de las mejores vacunas frente a esta tentación, al igual que lo hará el filósofo alemán Odo Marquard con quien mantiene puntos de vista coincidentes en más de una cuestión. Cfr. Marquard, O.: Individuo cit., p. 62. Ver también Apología cit.

[84] Certeau, M. de: La faiblesse cit., p. 120.

Thémata. Revista de Filosofía No53 (2016) pp.: 195-218. 
sociales, es raro que no se parta de la afirmación de que hoy ya no se cree en nada, que se ha perdido la fe en el proyecto común de una sociedad, que existe una crisis de la autoridad.

La sociedad de ayer comprendía una pluralidad de grupos ideológicos: organismos políticos, formaciones sociales, Iglesias, movimientos juveniles, etc. Un desierto de credibilidad ha sucedido a esta proliferación, allí mismo donde las fuerzas han sobrevivido a sus creencias y las utilizan todavía (pero más con fines publicitarios que programáticos). ${ }^{85}$

Certeau advierte en sus textos que esta crisis de las instituciones es generalizada y afecta también a quienes como las «religiones, patrias y sindicatos han ejercido durante mucho tiempo estas dos funciones, enredadas la una en la otra: organizar prácticas y representar principios» ${ }^{86}$. Nuestro autor no se engaña respecto a la institución eclesial en la que vive. Tiene claro que, a pesar de las muchas voces que pretenden negarlo, esta crisis de autoridad alcanza también a la Iglesia. Pues si «las autoridades forman parte de la Iglesia y no son de otra naturaleza que ella» ${ }^{87}$, una carga de profundidad sobre la autoridad en general ha de afectar también a las concreciones eclesiales de la misma.

La cuestión de fondo consiste en que la Iglesia no sea ya el cuerpo del sentido, que los cristianos sean los viudos de la institución eclesial. Repitamos una vez más que son muchas las grandes instituciones que están experimentando la misma crisis. ${ }^{88}$

Pero, ¿qué es lo que produce esta crisis en la que las autoridades pierden los depósitos de creencias que las sostenían? Por un lado, la incoherencia entre el decir y el hacer. Incoherencia que se hace notoria y clamorosa al comprobarse la diferencia que existe entre lo que afirman quienes ejercen la representación de la institución y lo que hacen aquellos que reciben y sostienen esas afirmaciones (con su consentimiento y su aprobación o desaprobación a través de actos concretos ${ }^{89}$ ). Por otro lado, el conocimiento de la corrupción interna a ellas mismas, que es como una incoherencia con mayúsculas. Y por último, la escasa adaptación de los términos del contrato que sustenta la institución respecto a las circunstancias reales del momento.

[85] Certeau, M. de: La culture cit., p. 115.

[86] Certeau, M. de: El estallido cit., p. 28.

[87] Certeau, M. de: La faiblesse cit., p. 117.

[88] Certeau, M. de: El estallido cit., p. 28.

[89] Certeau, M. de: La culture cit., p. 220.

Thémata. Revista de Filosofía $\mathrm{N}^{\circ} 53$ (2016) pp.: 195-218. 
Si se admite que una institución es siempre un modo de reglamentación entre oferta y demanda, no sorprenderá que los acuerdos anticuados y en vías de mutación tengan por signo o efecto una desestructuración de las instituciones. ${ }^{90}$

Las consecuencias de esta crisis son aún difíciles de prever. En un primer momento sí que es posible constatar un gran vacío, que nace del hecho de que nadie puede garantizar el sentido perdido. Con la pérdida de la credibilidad la estructura de las sociedades se convierte en un cascarón vacío, pues ya no hay «una verdad que decir y que practicar» ${ }^{91}$. En esta desafección generalizada como dirá Certeau «ninguna institución está en una situación sacerdotal $»^{92}$, ninguna es capaz de balbucear siquiera un discurso que ofrezca un sentido creíble sobre lo real. Y no obstante, de la lectura de la obra certeauniana queda la constancia de que la creencia no se pierde ${ }^{93}$. Certeau confirma que en nuestra sociedad quedan, por dispersos que estén, «restos de adhesión» ${ }^{94}$, que pueden ser el germen de nuevas instituciones. Por apagada e incrédula que parezca, en nuestra vida común sigue presente la energía que lleva a los individuos a creer en algo, a configurar sus comportamientos en función de mensajes creíbles.

Las afirmaciones de sentido toman hoy la figura de un "resto" del que se habrían desinfectado los campos científicos. Sin embargo, excluidas de los laboratorios, éstas entran en los circuitos de la explotación comercial. A una racionalización del saber parece corresponderle una folclorización de las verdades de antaño» ${ }^{95}$.

Cuanto tiempo tardarán en reorganizarse estos restos o de qué modo lo harán son preguntas pertinentes que, sin embargo, no tienen respuesta.

\section{Conclusiones}

Desde la perspectiva de Michel de Certeau, la política es un espacio de encuentro y conflicto. En sus obras se observa una apología encendi-

[90] Ibidem, pp. $113 \mathrm{~s}$.

[91] Certeau, M. de: La faiblesse cit., p. 118.

[92] Ibídem, p. 248.

[93] Es lo mismo que piensa Ortega cuando afirma que "no es posible que una fe muera si no es porque otra fe ha nacido", Ortega y Gasset, J.: Ideas cit., p. 39. Convendría analizar con detalle la posible relación entre el término creencia en Certeau y el de vigencia colectiva en Ortega. Cfr. Ortega y Gasset, J.: La rebelión cit., pp. 212 ss; El libro cit., p. 29.

[94] Certeau, M. de: L'invention cit., p. 260.

[95] Certeau, M. de: Le faiblesse cit., p. 187.

Thémata. Revista de Filosofía $\mathrm{N}^{\circ} 53$ (2016) pp.: 195-218. 
da de la diferencia y una perspectiva polemológica de la convivencia social, convirtiéndose ambas en rasgos definitorios del planteamiento social de Certeau dentro de la dimensión política de su antropología del creer.

Es también una pieza clave de esta reflexión antropológica la toma en consideración de las instituciones, que en el pensamiento certeauniano tienen un papel protagonista. En un marco como la actual sociedad occidental, en el que las previsiones del desmoronamiento de las instituciones han ido mucho más lejos de lo que era posible imaginar en los años ochenta del pasado siglo, cobran una especial relevancia los vínculos detectados por Certeau entre instituciones y creencias. El descreimiento generalizado de Occidente ante los discursos de sus instituciones (tanto estatales como religiosas), contrasta fuertemente con el resurgir de fundamentalismos religiosos y políticos en otras partes del mundo, y augura un tiempo de intensos cambios. La lectura de la obra de Michel de Certeau puede ser de gran ayuda para afrontarlos.

\section{Referencias bibliográficas}

Arendt, H.: Sobre la violencia. Madrid: Alianza Editorial, 2010.

Blumenberg, H.: Las realidades en que vivimos. Barcelona: Paidós/ ICE-UAB, 1999.

Buber, M. Yo y Tú. Madrid: Caparrós Editores, $2005^{4}$.

Certeau, M. de: «Introduction» en Surin, J.-J.: Guide Spirituelpour la perfection. París: Desclée de Brouwer, 1966.

Certeau, M. de: Laprise de parole et autresécritspolitiques. París: Seuil, 1994(1968).

Certeau, M. de: L'étrangeroul uniondans la différence. París: Seuil, 2005 (1969).

Certeau, M. de: La possession de Loudun. París: Gallimard, 1970.

Certeau, M. de: L'Absent de l'histoire. París: Mame, 1973.

Certeau, M. de: La culture aupluriel. París: Seuil/C. Bourgois, 1993 (1974).

Certeau, M. de y Domenach, J.-M.: El estallido del cristianismo. Buenos Aires: Sudamericana, 1974.

Certeau, M. de: L'écriture de l'histoire. París: Gallimard, 1975.

Certeau, M. de: L'invention du quotidien. 1. Arts de faire. París: Gallimard, 1980.

Certeau, M. de; Giard, L. y Mayol, P.: L'invention du quotidien. 2. Habiter, cuisiner. París: Gallimard, 1994 (1980).

Certeau, M. de: La fable mystique. XVIe-XVIlesiècle. París: Gallimard, 1982.

Certeau, M. de: La faiblesse de croire. París: Seuil, 1987.

Certeau, M. de: Histoire et psychanalyse entre science et fiction. París: Gallimard, 2002 (1987).

Certeau, M. de: Le lieu de l'autre. Histoire religieuse et mystique. París: Seuil/Gallimard, 2005. 
Certeau, M. de: "L'actif et le passif des appartenances" en Esprit, junio 1985, pp. 155-171.

Freud, S.: "Análisis terminable e interminable» en Freud, S.: Obras Completas. Buenos Aires: Amorrortu, 2004, vol. 23, pp. 211-254.

Giard, L.: «Mystique etpolitique, oul'institutioncomme objet second», en Giard, L.; Martin, H. y Revel, J.: Histoire, mystique et politique. Michel de Certeau. Grenoble: JérômeMillon, 1991 pp. 9-45.

Giard, L.: «Par quoidemaindéjà se donne à naître» en Certeau, M. de: La prise de parole et autresécritspolitiques. París: Seuil, 1994 (1968) pp. 7-26.

Giard, L.: «Histoired'unerecherche» en Certeau, M. de: L'invention du quotidien. 1. Arts de faire. París: Gallimard, 1980, pp. I-XXX.

Giard, L.: "CherchantDieu» en Certeau, M. de: La faiblesse de croire. París: Seuil, 1987 pp. 7-24.

Giard, L.: "Un chemin non tracé» en Certeau, M. de: Histoire et psychanalyse entre science et fiction. París: Gallimard, 2002 (1987) pp. 11-50.

Marquard, O.: Apología de lo contingente. Valencia: Institució Alfons el Magnànim, 2000.

Marquard, O.: Adiós a los principios. Valencia: Institució Alfons el Magnànim, 2000.

Marquard, O.: Individuo y division de poderes. Madrid: Trotta, 2012.

Moingt, J.: "Respecter les zonesd'ombrequidécidémentrésistent" en Recherches de ScienceReligieuse, 91/4, 2003, pp. 577-587.

Ortega y Gasset, J.: El libro de las misiones. Buenos Aires: EspasaCalpe Argentina, $1945^{4}$.

Ortega y Gasset, J.: La rebelión de las masas. Madrid: EspasaCalpe, $1956^{13}$.

Ortega y Gasset, J.: Ideas y creencias. Madrid: Austral, $1968^{7}$.

Ortega y Gasset, J. España invertebrada. Barcelona: Espasa, $2013^{31}$.

Revel, J.: «Michel de Certeau: l'institution et son contraire» en Giard, L.; Martin, H. y Revel, J.: Histoire, mystique etpolitique. Michel de Certeau. Grenoble: JérômeMillon, 1991 pp. 109-128.

Schopenhauer, A.: El arte de ser feliz. Explicado en cincuenta reglas para la vida. Barcelona: Herder, 2007.

Sloterdijk, P.: El desprecio de las masas. Ensayo sobre las luchas culturales de la sociedad moderna. Valencia: Pre-textos, Valencia, 2002.

Unamuno, M. de: Sobre el sentimiento trágico de la vida. Madrid: Alianza, 2007.

Villacañas, J.L.: Historia del poder político en España. Barcelona: RBA, 2014. 